\title{
IMAGING IN COOPERATION WITH MODELING OF SELECTED DEFECT MECHANISMS DURING FIBER LASER WELDING OF STAINLESS STEEL
}

\author{
Paper 1701
}

\author{
Alexander F. H. Kaplan ${ }^{1}$, Elin M. Westin², Greger Wiklund ${ }^{1}$, Peter Norman ${ }^{1}$ \\ ${ }^{1}$ Department of Applied Physics and Mechanical Engineering, \\ Luleå University of Technology, SE-971 87 Luleå, Sweden \\ ${ }^{2}$ Outokumpu Stainless, Avesta Research Center, P.O. Box 74, SE-774 22 Avesta, Sweden
}

\begin{abstract}
Fiber laser welding of stainless steel was studied for different joint configurations and gaps. The higher focusing capability of fiber lasers compared to traditional Nd:YAG and $\mathrm{CO}_{2}$ lasers creates different, usually smaller, keyhole and melt pool geometries. These geometrical aspects, accompanied by a different laser energy redistribution, are essential for the weld pool dynamics and the resulting joint, with or without defects. Typical defects identified during fiber laser welding were spatter, humping, or lack of material at the top or root.
\end{abstract}

High-speed imaging enables observation of the geometry and motions of the melt pool surface and keyhole during welding. This is illuminated by an additional diode laser permitting spectral filtering and also the metal vapor dynamics can be visualized. Mathematical modeling provides the possibility to estimate and study additional phenomena that are difficult to measure, such as effects inside the melt volume or the impact of surface tension forces on dynamic melt motion. For recorded melt surface motion images, in particular, the corresponding surface tension forces and other mechanisms can be estimated by cooperative complementary modeling, enabling to draw conclusions. This advanced method was carried out for the different joint and defect cases studied, resulting in an illustrated theoretical description of the observed physical phenomena.

\section{Introduction}

A characteristic advantage of laser welding is the capability of distribution of the energy (via the keyhole) deep into the material to generate a narrow, deep weld [1,2]. For the new high brightness laser types, namely the fibre laser and the disc laser, this aspect ratio becomes even more pronounced,[3-6] owing to their excellent focusing capabilities along with high power. In particular, the smaller the beam (and keyhole) and the higher the speed the narrower becomes the weld. A narrow process not only decreases the melting rate and in turn the energy required, but higher speed also reduces the lateral heat conduction loss.

The power density of the focused laser beam, for example, on the surface used to be a suitable property for defining process thresholds, e.g. for initiating deep penetration welding of the order of $10^{6} \mathrm{~W} / \mathrm{cm}^{2}$. The Nd:YAG laser forms a keyhole at lower values than the $\mathrm{CO}_{2}$ laser, and steel at lower values than aluminum. Plasma shielding during $\mathrm{CO}_{2}$-laser welding is associated with values beyond the order of $10^{7} \mathrm{~W} / \mathrm{cm}^{2}$.

While traditional cw-lasers used to operate in the range of power densities of $5 \cdot 10^{5}-5 \cdot 10^{6} \mathrm{~W} / \mathrm{cm}^{2}$, the new lasers reach higher values. In the present study a $15 \mathrm{~kW}$ fiber laser, focused to a spot diameter of $\mathrm{w}_{0}=400 \mu \mathrm{m}$ is used, leading to a maximum power density of $\mathrm{I}_{0}=1.19 \cdot 10^{7} \mathrm{~W} / \mathrm{cm}^{2}$. In the near future the here presented case will be repeated for a $200 \mu \mathrm{m}$ spot diameter, i.e. $\mathrm{I}_{0}=4.78 \cdot 10^{7} \mathrm{~W} / \mathrm{cm}^{2}$.

Several studies [6] have shown that welding with high brightness lasers often causes underfill (grooving, i.e. significant lack of material), requiring e.g. defocusing, thus confining the above advantages. Consequently, the influence of the beam parameters such as power, power density or focal plane position has been studied for fiber laser welding of $8 \mathrm{~mm}$ thick stainless steel. For improved understanding of the phenomena, highspeed imaging is applied, accompanied by mathematical modeling to estimate certain phenomena.

\section{Method}

The applied methodological approach was as follows: As the first part of the study a series of bead-on-plate (BOP) welds (denominated C1-C7) was performed for different power levels, P, either by keeping the speed, $\mathrm{v}$, constant (three welds) or by the line energy $\mathrm{P} / \mathrm{v}$ (five welds), as shown in Figure 1. 


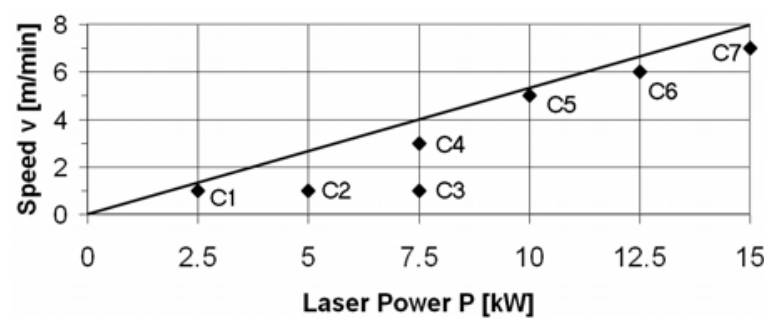

Figure 1 Welding speed and beam power of the seven studied operating points

One particular problem identified for high brightness lasers is the thermal focus shift of the focal plane towards the optics due to stronger heating (thus deformation and change of the refractive index) of any optical element [3]. The focal shift can depend on the beam power and on the power-on duration of the laser along with cooling time during breaks. It may also be affected by the design of optical elements and mountings and any pollution of the optics. Thus the focal shift is not a fixed offset value. For the laser and optics used in this work, the focal plane was tested to shift $1.5 \mathrm{~mm}$ from $1 \mathrm{~kW}$ to $10 \mathrm{~kW}$.

To partially overcome this uncertainty, the focal plane position $\mathrm{z}_{0}$ was linearly varied during a single weld pass from $-10 \mathrm{~mm}$ to $+10 \mathrm{~mm}$ (zero: at the surface, negative: into the material). By this measure any relevant focal position is considered when welding and by assuming symmetry along the weld path the focal plane position can roughly be identified. Thus, a single weld pass represents a wide range of focal positions. The change of the focal plane position is assumed to be sufficiently slow so that quasi-steady state process conditions are maintained throughout the weld. For the seven welds C1-C7 the surface appearance (particularly full penetration and underfill) is studied and compared to fundamental properties such as line energy or beam power density at the surface in order to study whether a certain criterion corresponds to a specific appearance. High-speed imaging of the seven welds was carried out for acquiring additional information.

In the second part of the study, different melt dynamics were categorized using high speed imaging and the four most characteristic spatter types were selected for deeper investigation. Beside qualitative observation of the phenomena, quantitative evaluation of the four types was carried out over a selected period with about 8-15 drop events. This evaluation not only provides facts on the process behavior, it also facilitates mathematical modeling that can reveal additional information. Such approach of starting with experimental facts as a base for modeling of a certain mechanism was recently demonstrated to be very powerful [7].
From the obtained information it is studied whether certain properties are typical for the four different types of spatter. As a research hypothesis, different properties associated with different types of spatter would advance the development of a theoretical description of the causes for the spatter (and underfill). Eventually, a new method [8], the Bifurcation Flow Chart (BFC) is applied, suitable for documenting results and developing a general theoretical description of laser welding. For this method it is essential to identify (e.g. by high speed imaging) the essential phenomena that determine whether a certain mechanism occurs and in turn causes a defect. Ideally, a generally valid theory on spatter and its suppression is desired.

\section{Experimental Set-up}

A $15 \mathrm{~kW}$ Yb:fiber laser is used (IPG Laser), having a beam parameter product of $10.4 \mathrm{~mm} \cdot \mathrm{mrad}$, the beam being guided by a fiber with a core diameter of $200 \mu \mathrm{m}$. The focusing optics used (Precitec) has a focal length of $300 \mathrm{~mm}$, while the collimator is $150 \mathrm{~mm}$, thus creating a focal spot diameter of $400 \mu \mathrm{m}$ and a Rayleigh length of $\pm 3.8 \mathrm{~mm}$. The processing head was tilted $7^{\circ}$ ahead, i.e. in trailing position to reduce the risk of beam backscattering damage of the fiber. $8 \mathrm{~mm}$ thick stainless steel of the common grade AISI 304 was welded BOP (sample size $100 \mathrm{~mm} \times$ $100 \mathrm{~mm}$ ). Argon shielding gas was delivered at a flow rate of $12 \mathrm{l} / \mathrm{min}$ through a tube employed in stitching welding direction opposite to the laser inclination, thus above the weld pool. Argon was used as root shielding gas flow was at $8 \mathrm{l} / \mathrm{min}$ flow. Power, $\mathrm{P}$, speed, v, and focal plane position, $\mathrm{z}_{0}$, were varied as previously explained and shown in Figure 1.

High-speed imaging was carried out with a Redlake HS-X3 camera at 2000 frames per second, filtered for the illumination laser wavelength $(808 \mathrm{~nm})$. The camera was inclined $51^{\circ}$ from the surface (corresponding to a projection of the vertical dimension for all images shown), view from the side. A single pixel corresponds to $15.2 \mu \mathrm{m}$ (horizontally). The processing zone was illuminated, from the same side as the camera, by a diode laser beam (at a frequency of $2000 \mathrm{~Hz}$ ) with $500 \mathrm{~W}$ pulses of 0.5 us pulse length.

\section{Results and Discussion}

\section{Variation of the Power Density Distribution}

As the first part of the study the seven welds C1-C7 were carried out according to the parameters in Figure 1. For each weld the focal plane position was varied from $\mathrm{z}_{0}=-10 \mathrm{~mm}$ to $\mathrm{z}_{0}=+10 \mathrm{~mm}$ (disregarding thermal focus shift). The caustics of the focused laser 
beam are shown in Figure 2(a), thus the spot size on the surface dependent on the focal plane position. The corresponding average power density $\mathrm{I}_{0}=4 \mathrm{P} / \mathrm{w}^{2} \pi$ as a function of the position is plotted in Figure 2(b). Note that (step index) fiber-delivered laser beams have a top-hat power density profile in the focal plane but when being out of focus rapidly change to a Gauss-like profile. As the seven welds were arranged equidistant next to each other, with increasing power, and as the focal plane position was linearly varied for each of them, lines of constant power density can be plotted according to the experimental geometry, as shown in Figure 2(c). Note that the step is caused by the fact that experiment C3 and C4 have the same power. The top surface appearance of the welds is shown in Figure 2(d) where also the line of constant power density $6 \cdot 10^{6} \mathrm{~W} / \mathrm{cm}^{2}$ is plotted.

The weld width narrows from start and end to the middle of the sample where the surface experiences the smallest spot size. Compared to C1, the welds C2 and C3 become very wide, as the power is increased, but not the speed, i.e. the line energy $\mathrm{P} / \mathrm{v}$ is doubled and tripled. In contrast, for the other welds where the line energy is kept approximately constant, the weld width narrows for increasing speed, as the lateral heat losses become less important. Underfill along with spatter deposition can be observed for certain domains of stronger focusing, however, not symmetrically, but shifted towards focusing above the surface. Domains of drop-free homogeneous underfill can be distinguished from domains where large drops were deposited in an irregular manner.

The surface appearance of the root side is shown in Figure 3(a). Full Penetration was only achieved for sufficient power and suitable focus position. The weld C1 did not weld through at all $(2.5 \mathrm{~kW}$ was insufficient) and C2 (5 kW) is just at the limit of succeeding (in agreement with the estimation that the maximum penetration depth in [mm] is 1.5 times the beam power in $[\mathrm{kW}])$. In contrast, C3 $(7.5 \mathrm{~kW})$ welds through along the whole weld, despite severe defocussing, owing to the low speed and high line energy. The welds C4 to C7, where the line energy is kept constant have a similar range of full penetration, approximately in a focal plane interval from $-5 \mathrm{~mm}$ to $+5 \mathrm{~mm}$.

From the symmetric middle of the full penetration range a common focal plane position (on the top surface) is assumed, indicating a focal plane shift according to the line drawn in Figure 3(a). This line follows qualitatively the trend that increasing power shifts the focus towards the optics, i.e. more left in the shown welds. Note that the picture was inverted to correspond to Figure 2 with the start and focus low from the left.

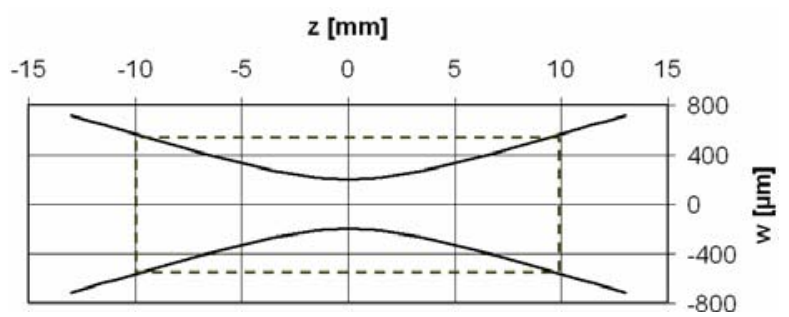

(a)

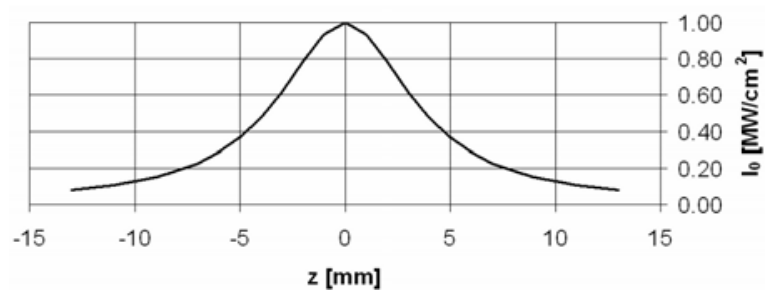

(b)

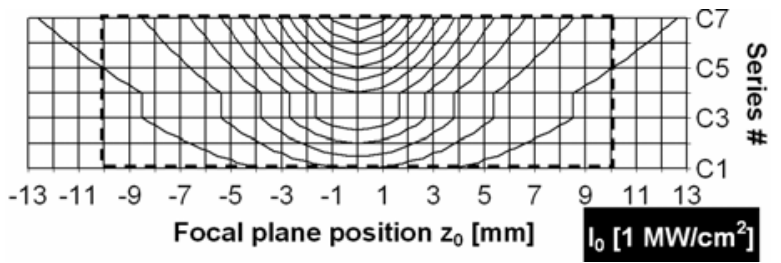

(c)

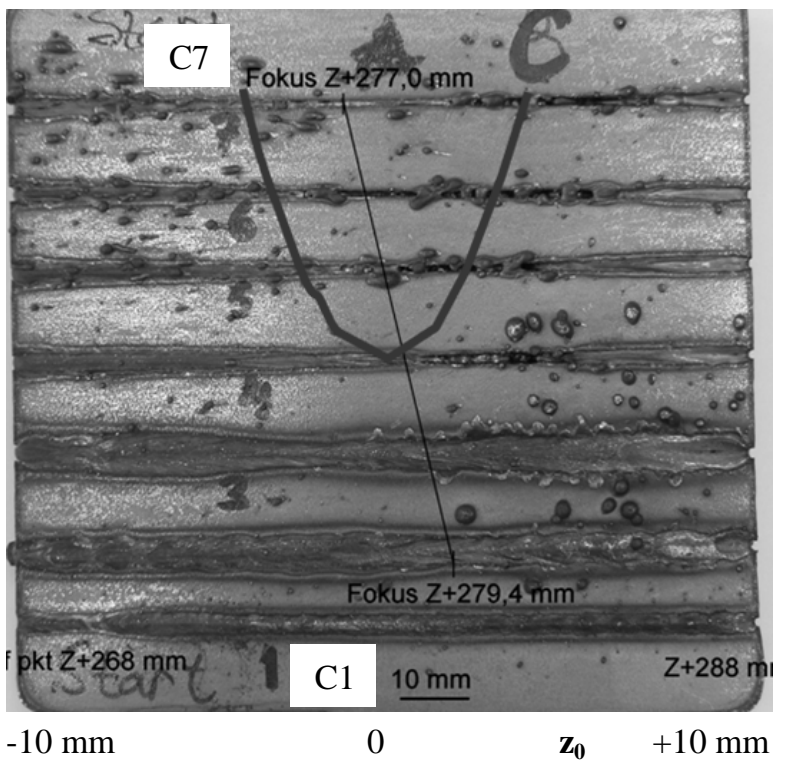

(d)

Figure 2 (a) Diameter of the focused laser beam as a function of the z-position (caustics), (b) average power density as a function of the z-position, (c) lines of constant power density $\mathrm{I}_{0}$ according to the seven welds C1-C7, (d) top surface appearance of the seven welds (C1 at the bottom and C7 at the top) 
Different formulations of the "line energy" (the dimension is not Joule, but has an energetical meaning) were plotted (in lines of constant values) and compared with the welds:

$$
\begin{aligned}
& E=\frac{P}{v} \\
& E^{\prime}=\frac{P}{v d} \\
& E^{\prime \prime}=\frac{P}{w_{0} v d} \\
& E^{\prime \prime \prime}=\frac{P}{w_{0}^{2} v d}
\end{aligned}
$$

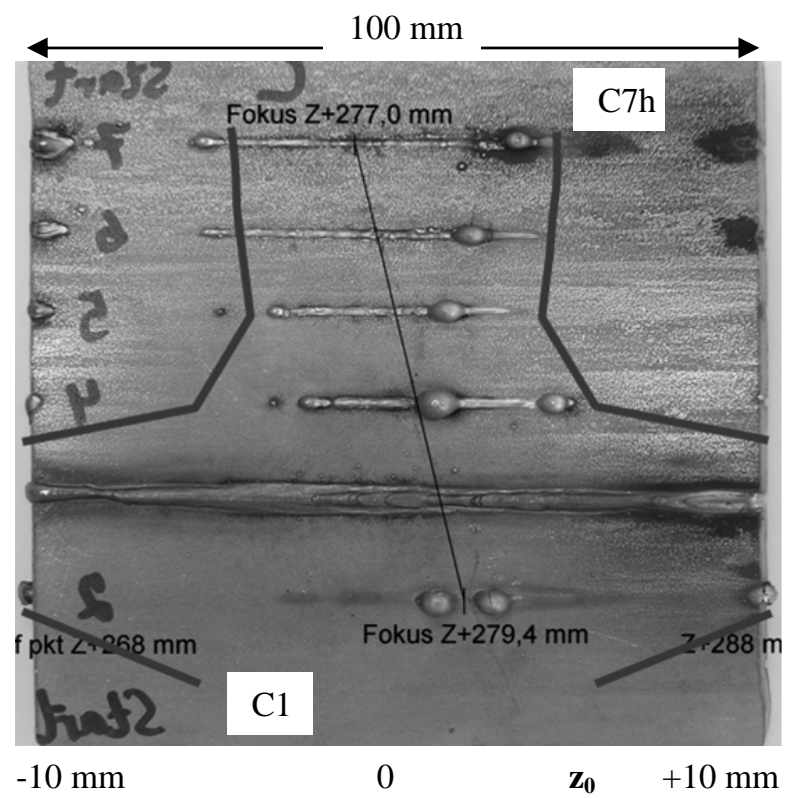

(a)

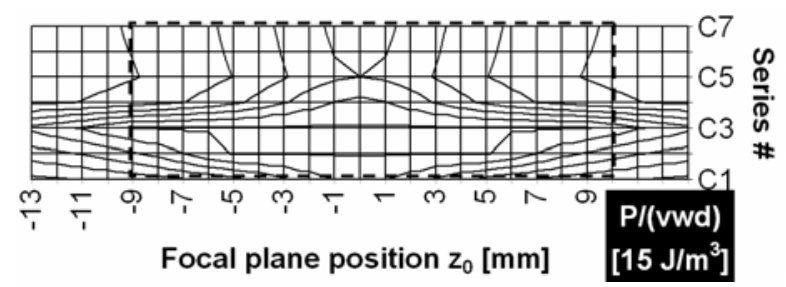

(b)

Figure 3 (a) Root surface of the seven welds, starting from the left; the line of constant $\mathrm{P} /(\mathrm{wvd})=30 \mathrm{~J} / \mathrm{m}^{3}$ is shown; possible focus position shift indicated;

(b) corresponding lines of constant value $\mathrm{P} /(\mathrm{wvd})$

In Figure 2(b) a line of constant value $\mathrm{P} /(\mathrm{wvd})=$ $30 \mathrm{~J} / \mathrm{m}^{3}$ is plotted (not corrected by the thermal focus shift). A quite good correlation of the line with the limits of full penetration is revealed, indicating that full penetration is mainly governed by the corresponding parameters. An additional criterion is sufficient beam power, i.e. more than $5 \mathrm{~kW}$ in the present case.

It is interesting to note that even at the root side regions of underfill are present, thus severe spatter ejection does not only take place at the top but also at the root. Figure 4 shows several typical cross-sections of the welds. Underfill can be clearly seen. Of particular importance is that underfill can be created at the root side, while the top surface appearance can be a sound weld, Figure 4(g). (a)
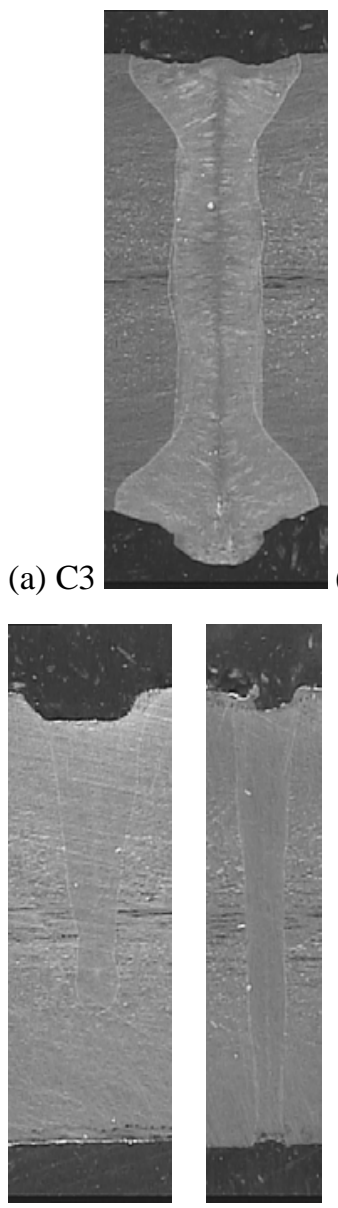

(d) C7d

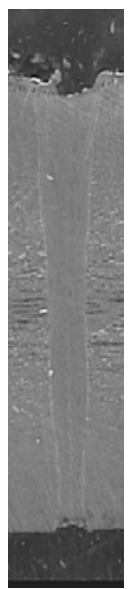

(e) $\mathrm{C} 7 \mathrm{e}$ (b) C4b

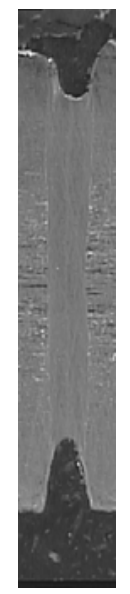

(f) $\mathrm{C} 7 \mathrm{f}$

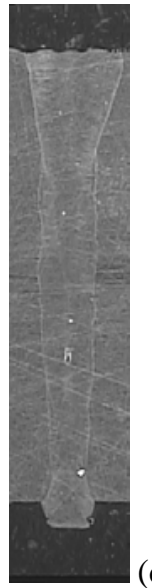

(c) $\mathrm{C} 5$

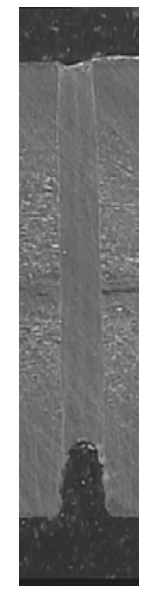

(g) $\mathrm{C7g}$

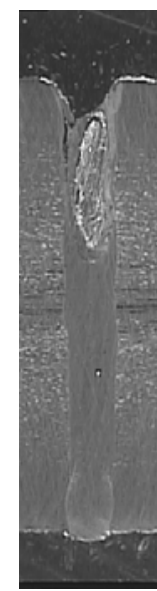

(h) C7h
Figure 4 Cross-section of typical welds (thickness $8 \mathrm{~mm}$ ): (a) $\mathrm{P}=7.5 \mathrm{~kW} / \mathrm{v}=1 \mathrm{~m} / \mathrm{min} / \mathrm{z}_{0}=-1.5 \mathrm{~mm}$,

(b) $7.5 / 3 / 0$, (c) $10 / 5 /-1$, (d) $15 / 7 /-7$, (e) $15 / 7 /-4$, (f) $15 / 7 /-0.5$, (g) $15 / 7 / 0$, (h) $15 \mathrm{~kW} / 7 \mathrm{~m} / \mathrm{min} /+5 \mathrm{~mm}$

Lower line energy and defocusing leads to significant widening of the weld, particularly of the top part (nail shape), but even under such conditions can result in underfill. Full penetration of the whole weld was obtained if the line energy was very low (C3, factor three lower than the usual energy or speed). 


\section{Study of Four Types of Spatter}

For all seven welds, apart from lack of penetration, underfill due to massive spatter is the main welding defect. Thus the drop formation and ejection mechanism is studied more thoroughly. All experiments were repeated, now observed by high-speed imaging. The obtained results were very similar. The welds with a power of $15 \mathrm{~kW}(7 \mathrm{~m} / \mathrm{min})$ and $7.5 \mathrm{~kW}(3 \mathrm{~m} / \mathrm{min})$ were studied in more detail. The weld top and root surface appearances are shown in Figure 5, including a categorization of the weld quality along the path.

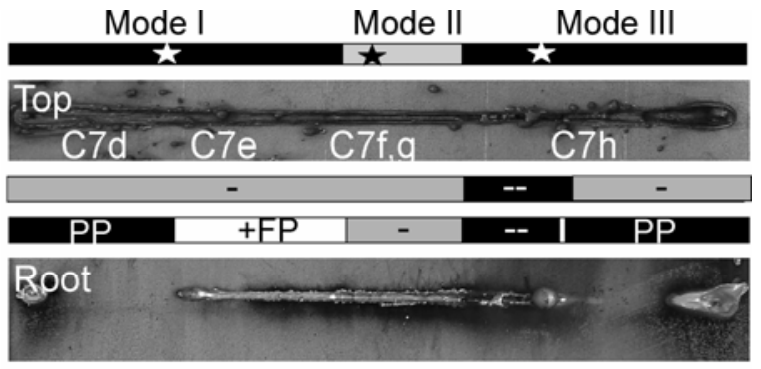

(a)

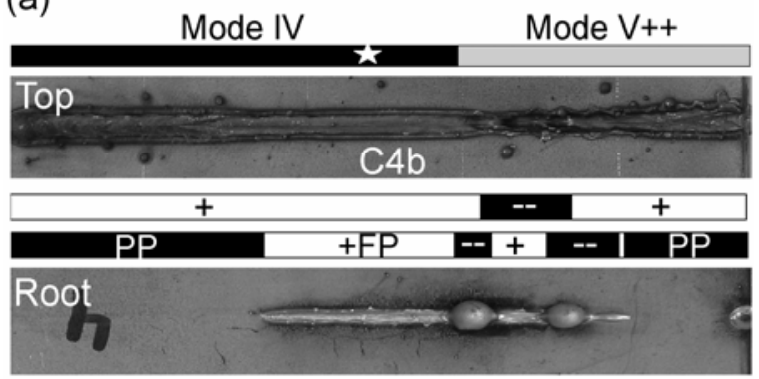

(b)

Figure 5 Top and root surface appearance for (a) $15 \mathrm{~kW}$ and (b) $7.5 \mathrm{~kW}$, identified quality ranges (+/-; Full/Partial Penetration), range of modes, selected imaging interval $(\star)$ for the four modes studied

The high-speed images of all welds showed several different types of spatter ejection mechanisms. The four most significant types, Figure 6, were studied in more detail. The locations corresponding to the sequences analyzed are marked in Figure 5. They represent significant parts of the welds. Mode I, II and III are from the $15 \mathrm{~kW}$ weld while Mode IV is from the $7.5 \mathrm{~kW}$ weld. Mode II and IV have a focus position at the surface, Mode I and III have a focus position about $5 \mathrm{~mm}$ below and above the surface, respectively. Mode IV corresponded to good welding results and Mode I formed slight underfill, while heavy spatter occurred for Mode II and III, causing significant underfill.

A typical drop ejection sequence (in 1 ms-steps) for each of the four modes is shown in Figure 7. Note that the brightness and contrast level of the images were post-processed from $50 \%$ to $77 \%$ and $89 \%$, respectively, for better visibility of the melt motion. For several images it is difficult to see the keyhole.

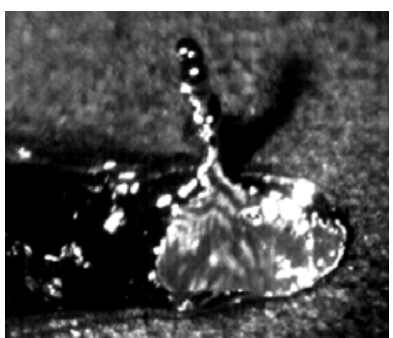

(a)

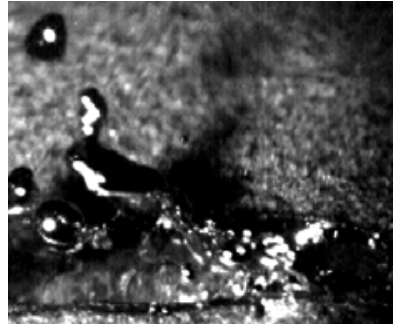

(c)

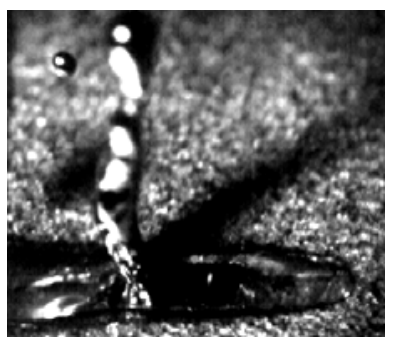

(b)

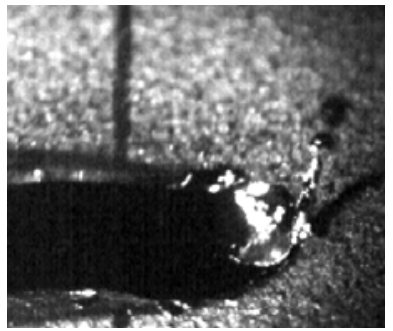

(d)
Figure 6 HS image of the four types of spatter studied: (a) Mode I ( $\left.15 \mathrm{~kW}, \mathrm{z}_{0}<0\right)$, (b) Mode II $\left(15 \mathrm{~kW}, \mathrm{z}_{0}=0\right)$, (c) Mode III (15 kW, $\left.\mathrm{z}_{0}>0\right)$, (d) Mode IV (7.5 kW, $\left.\mathrm{z}_{0}=0\right)$

Although the keyhole, melt and drop sizes appear different, the magnification is identical for all images. The different focal plane positions, powers and speeds have created clearly different geometries that appear to be essential for the melt dynamics. For Mode I the keyhole is very large, Figure 6(a), due to the defocused but intense beam. The beam diameter at the surface is about $650 \mu \mathrm{m}$ and the power density about $4 \cdot 10^{6} \mathrm{~W} / \mathrm{cm}^{2}$. During Mode III the surface experiences the same beam properties. For Mode I the focus is $5 \mathrm{~mm}$ into the material, thus the beam converges (and probably guides the keyhole strongly). For Mode III the focus is $5 \mathrm{~mm}$ above the surface, thus the beam diverges and becomes less intense, making guidance of the keyhole and process less strong. Note that the uncertainty of the thermal focus shift can have moved the beam 1-2 mm upwards for all modes, thus making Mode I even stronger (more focused) compared to Mode III. For Mode III only a small keyhole is observed, the dark front in Figure 6(c).

Mode II and Mode IV experience the expected small keyhole corresponding to the focused beam with the diameter $\mathrm{w}_{0}=400 \mu \mathrm{m}$ at the surface, although at double power and intensity for the former. For all four modes the keyhole exit experiences strong fluctuations. 
Mode I
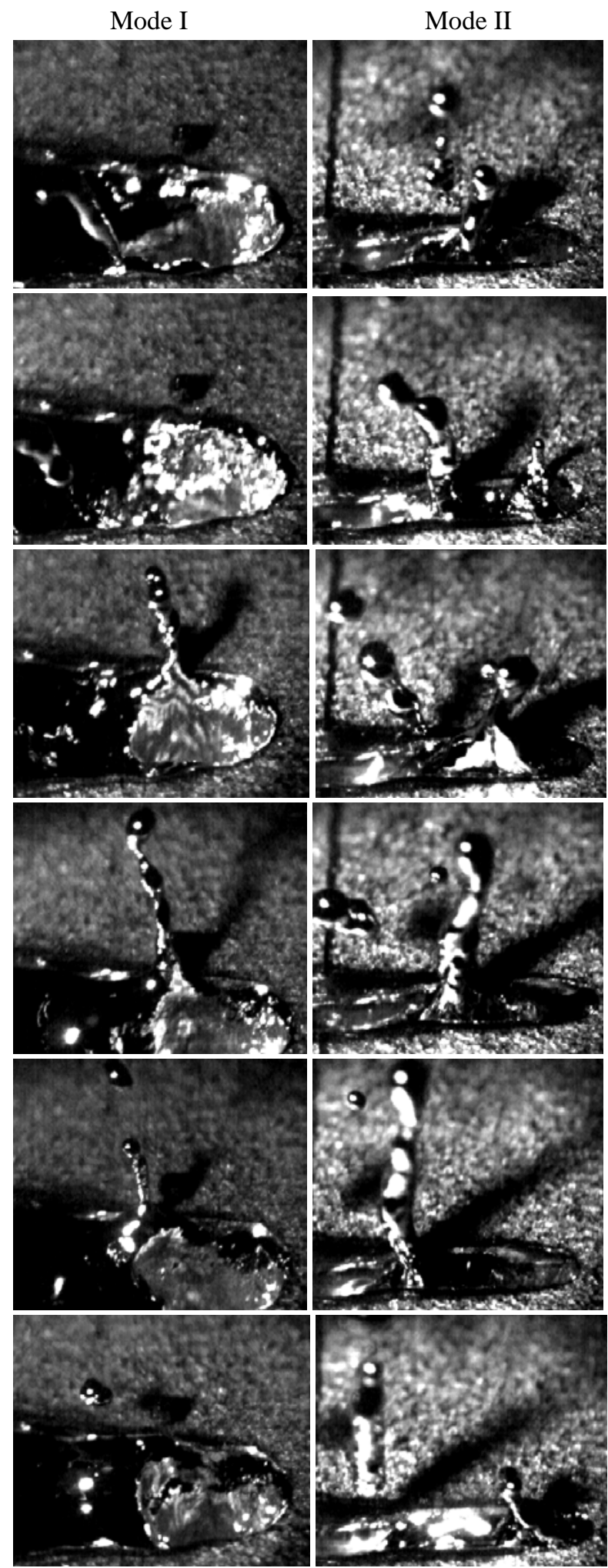

Figure 7 High speed images of a typical spatter sequence (1 ms-steps) for (a) Mode I (15 kW, $\left.\mathrm{z}_{0}<0\right)$, (b) Mode II $\left(15 \mathrm{~kW}, \mathrm{z}_{0}=0\right)$

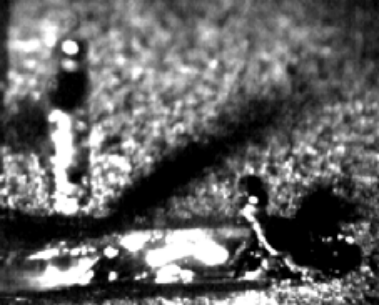

Mode III
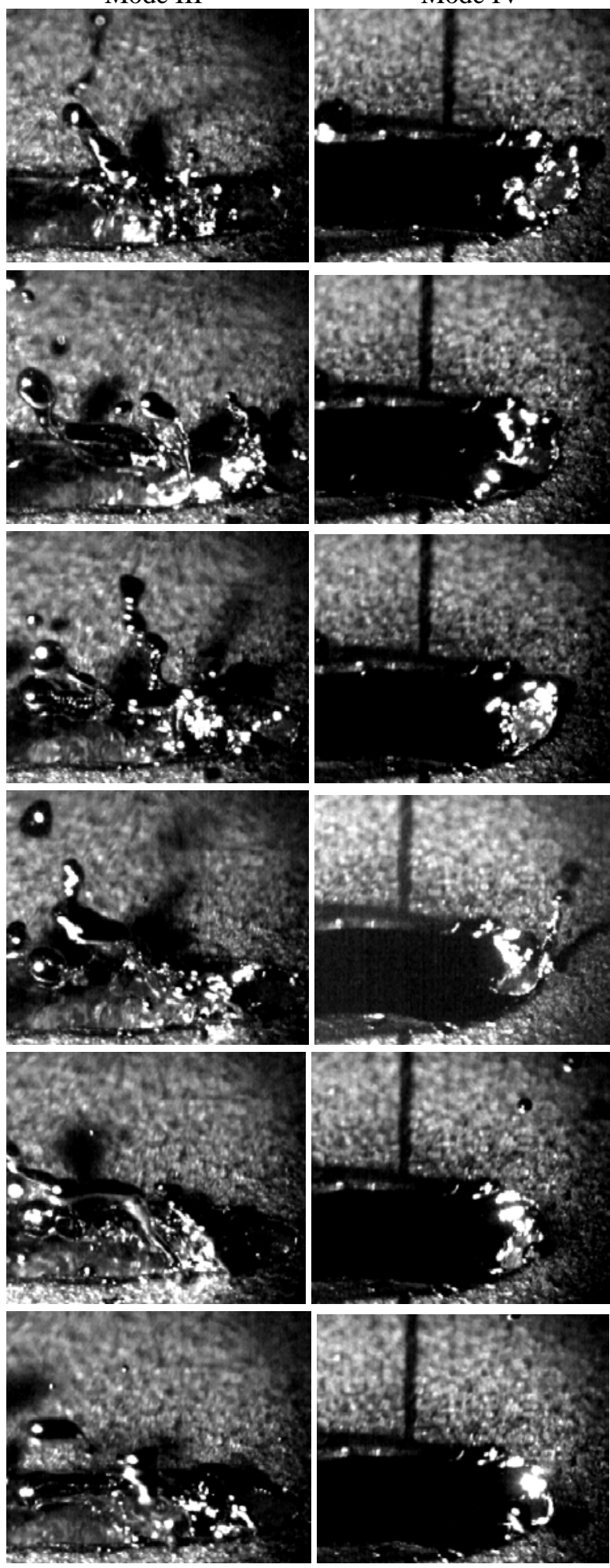

Figure 8 High speed images of a typical spatter sequence (1 ms-steps) for (a) Mode III (15 kW, $\left.\mathrm{z}_{0}>0\right)$,

Mode IV
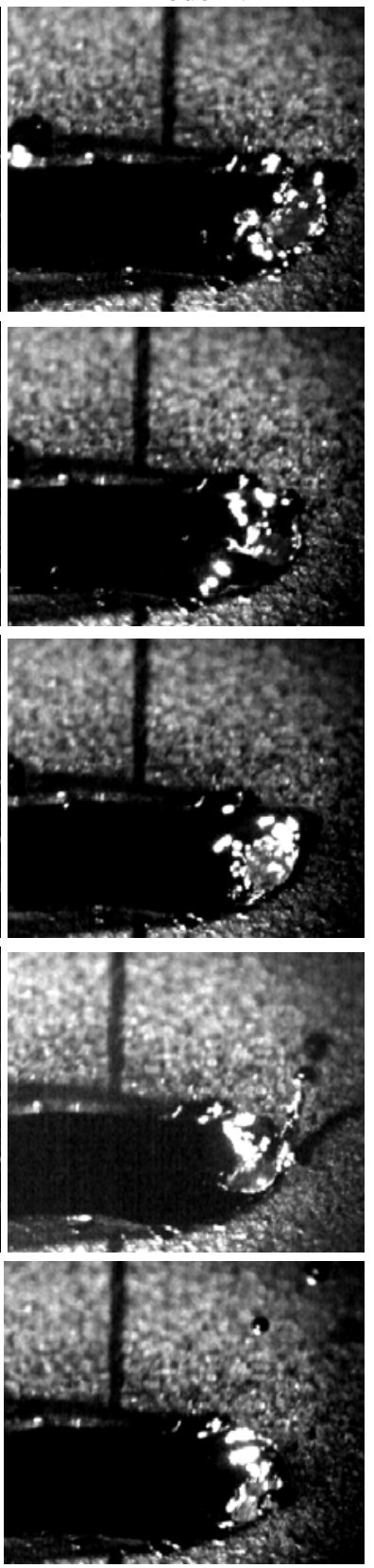

(b) Mode IV $\left(7.5 \mathrm{~kW}, \mathrm{z}_{0}=0\right)$ 
For Modes I and II, the melt width is almost solely governed by the keyhole size, slightly wider. In addition, only a very thin melt film can be observed in front of the keyhole. The continuously melted material is rapidly redirected around the keyhole by the evaporation recoil pressure. The conditions are less constrained for Mode III where some melt environment can be seen around the keyhole, leading to a wider melt pool (i.e. a widening in a different, thermodynamic way, while the wide melt in Mode I results from the large keyhole size). The conditions are very different for the low power/low speed Mode IV: In front of the little keyhole is a more significant melt layer that expands beside the keyhole to a rather wide melt pool compared to the keyhole size.

Imaging shows that this different melt environment around the keyhole is essential for the melt pool dynamics. The black appearance (low diffuse reflectivity) of the whole melt pool for Mode IV, Figures 6 and 8, is an indicator that the pool surface is plane and comparably calm, while for the high power Modes I-III violent melt dynamics continuously takes place. Some inclined surface elements of the heavily oscillating melt surface reflect the illumination laser beam to the camera, appearing as bright spots. Mode IV enables the upstreaming melted material to be redirected mainly in the horizontal plane to flow around the keyhole to the large trailing melt pool, while during the Modes I-III the confined melt environment is forced by the vapor recoil pressure to less regular motion, also in vertical direction.

Eventually, the various types of drop ejection take place that led to the categorization of these four modes. For Mode IV only little drops are occasionally ejected ahead of the keyhole, Figure 8(b). Most of the melt flows to the rear side of the melt pool. In contrast, during Mode II, for the same focusing conditions but twice the power and speed, melt flows upwards and a wave emerges behind the keyhole that creates a high vertical liquid column before it brakes into escaping large drops, Figure 7(b). This periodic phenomenon removes a significant fraction of melt, leading to deep underfill, Figure 4(f). Mode II has a very regular periodic drop ejection behavior. The mechanism is similar for Mode III, Figure 8(a), but the column is inclined rather than vertical and the drops separate earlier, accompanied by further less regular drop ejection mechanisms. Mode I is moderate and more versatile, as smaller drops are ejected beside the keyhole, although sometimes accompanied by larger drop ejection behind the keyhole. From the evaluation of the drop images several properties can be obtained, Figure 9. Due to a scaling gap three drops (Mode I: 1.5 $\mathrm{mm}^{3}$, II: 1.2, III: 1.9$)$ were inserted at the right border.

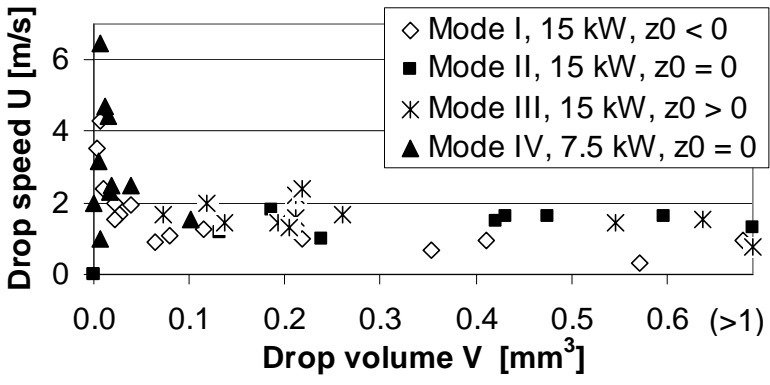

(a)

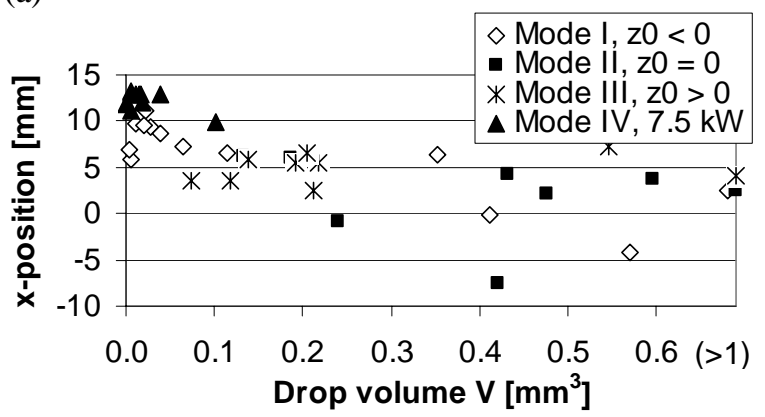

(b)

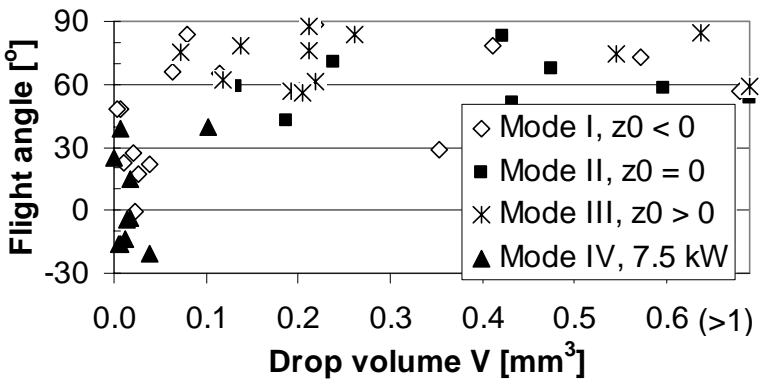

(c)

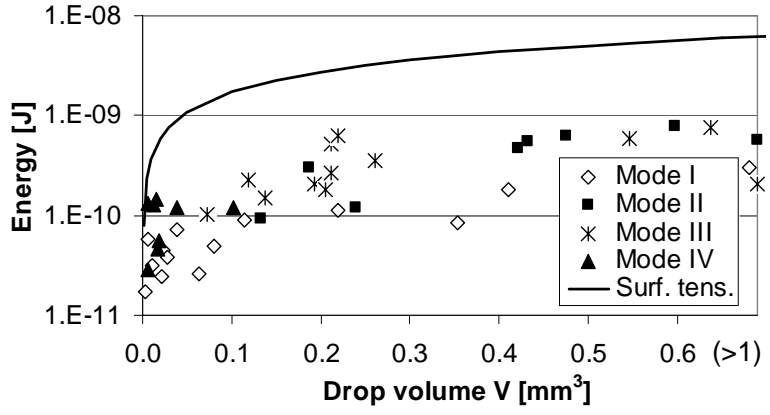

(d)

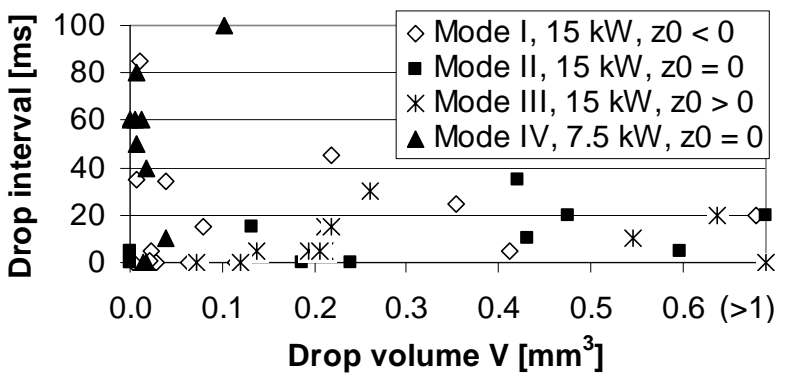

(e)

Figure 9 Evaluation of ejected drops as a function of the measured drop volume for the four modes: (a) drop 
speed, (b) traveling angle, (c) imaginary ejection $\mathrm{x}$-position at the surface centerline, (d) kinetic and surface tension energy of the drop, (e) time interval after the previous drop

For each of the four modes about 8-15 drops were measured from imaging with respect to size, position and velocity. As the images lose the third dimension (towards the camera), only their projected view is evaluated, inducing an uncertainty. Drops closer to the camera appear, for instance, larger and the velocity component towards the camera is not included. In the graphs the values are plotted as a function of the drop volume to identify characteristic correlations. The drop volume $\mathrm{V}=4 \mathrm{D}^{3} \pi / 3$, speed $\mathrm{u}$ and angle $\alpha$ (vertical defined zero) are directly measured properties. The $\mathrm{x}$-position is the virtual extension of the drop velocity vector to the $\mathrm{x}$-axis as an indicator for the origin of momentum (again one coordinate is neglected). The kinetic energy results to ( $\rho . . . s p e c i f i c$ mass density)

$$
E_{k i n}=V \rho \frac{u^{2}}{2}
$$

Similarly, the momentum of the drop could be derived. In Figure 9(e) the time interval from the previous drop event is plotted. Several trends can be seen: For Mode IV the drops are always small and often fast. During Mode I drops can be small and fast or large and slow. For Mode II even the relatively small drops have high energy, as they can be fast, while for Mode III large volume and mass is the reason for those drops that have high energy. For Modes I and IV the kinetic energy per drop is low. For Mode IV the drops are ejected at the keyhole front and directed vertically up or even in welding direction, for Mode I they are ejected upwards from the side while for Modes II and III they origin from behind the melt and are directed backwards, Figures 7 and 8.

Table 1 lists several average properties (indicative values due to limitations in the evaluation accuracy).

Table 1 Average drop properties for the four modes

\begin{tabular}{|c|r|r|r|r|r|}
\hline Mode & $\begin{array}{c}\text { Frequency } \\
{[\mathrm{Hz}]}\end{array}$ & $\begin{array}{c}\text { Volume } \\
{\left[\mathrm{mm}^{3} / \mathrm{ms}\right]}\end{array}$ & $\begin{array}{c}\text { Speed } \\
{[\mathrm{m} / \mathrm{s}]}\end{array}$ & $\begin{array}{c}\text { Angle* } \\
{\left[{ }^{\circ}\right]}\end{array}$ & $\begin{array}{c}\text { Energy } \\
{\left[10^{-8} \mathrm{~J} / \mathrm{s}\right]}\end{array}$ \\
\hline I & 424 & 105 & 1.63 & 48 & 4.7 \\
\hline II & 737 & 388 & 1.45 & 61 & 41.5 \\
\hline III & 1000 & 427 & 1.62 & 71 & 41.0 \\
\hline IV & 196 & 5 & 3.05 & 4 & 1.7 \\
\hline
\end{tabular}

* average per drop, otherwise accumulated per second

Table I reflects through the small removed volume that
Mode IV is extremely calm compared to the others, resulting in a sound weld surface. Mode I is clearly more moderate (less volume removed) than Modes II and III, which can hardly be distinguished from each other, despite their different visual appearance. Correspondingly, the kinetic energy driving the drop ejection is much higher for Modes II and III. This energy is generated from the laser through evaporation recoil pressure accelerating the melt.

\section{Development of a model on the melt dynamics}

The above observations and findings lead to a very fundamental question:

"What is the responsible mechanism causing spatter, of different types, and under which corresponding process conditions does it occur?"

The answer is neither obvious nor trivial. Hence a mathematical model is under development, not for the whole welding process, but for studying the local phenomena behind the spatter ejection in a complementary combination to high-speed imaging. In particular, the facts observed qualitatively and measured quantitatively from imaging are a safe input for the model.

As high-speed imaging enables to observe the larger melt surface motions, there is a need for an additional instrument for studying the motions in the melt volume, the invisible keyhole motions and the keyhole evaporation behavior. Mathematical models at three levels are consequently under development, all starting from experimentally observed data of the melt motion: A geometry-based model for the rising column breaking into drops, a model formulating the balances of momentum and energy and a streamline flow model, similar to [7]. The geometrical conditions, the drop ejection through a vertical column and a possible streamline generated from local keyhole boiling are illustrated in Figure 10.

The model is under development. In the following a basic outline is given along with a quantitative application of the model for the surface tension energy. For a first estimation an energy balance can be formulated, stating that at least the kinetic energy from the drop has to be released during a local evaporation event (by local laser energy $\mathrm{E}_{\mathrm{L}}$ ) where recoil pressure (or energy $E_{\text {rec }}$ ) was generated by corresponding evaporation of a number of $\mathrm{N}_{\mathrm{v}}$ particles with atomic mass $\mathrm{m}_{\mathrm{a}}$ and latent heat of evaporation $\mathrm{H}_{\mathrm{v}}$. Moreover, the new drop is an increase in surface area of the melt, consuming energy related to the surface tension $\sigma$ :

$$
\frac{D^{3} \pi}{6} \rho \frac{u^{2}}{2}+N_{v} m_{a} H_{v}+\sigma D^{2} \pi \leq E_{r e c} \leq E_{L}
$$




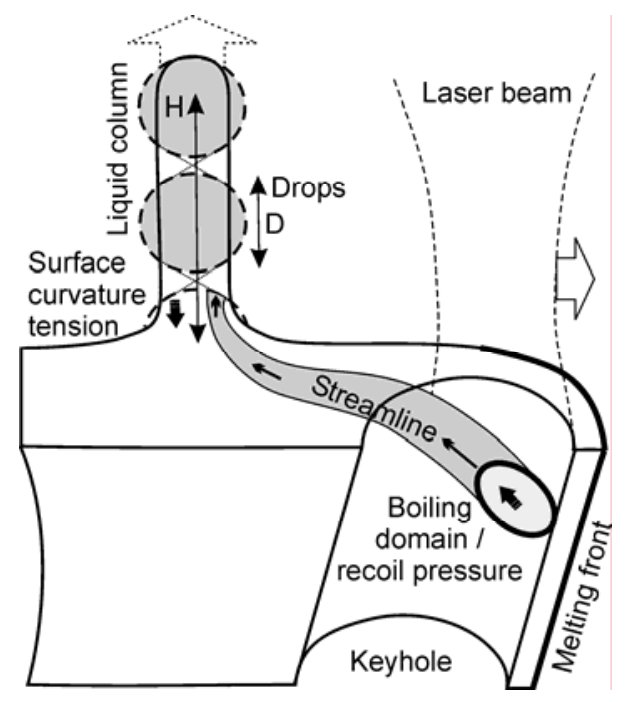

Figure 10 Illustrated theoretical description and modeling (geometry, streamline) of the boiling and momentum flow as the assumed origin for accelerating the melt to a column before necking and drop ejection

The calculated energy consumed for generating the additional surface of the drop as a function of the drop volume is plotted in Figure 9(d). The surface energy is one order of magnitude higher than the measured kinetic energy of the drops and is thus an essential threshold to be overcome for separating a drop.

A momentum balance can relate the drop momentum achieved from acceleration of the melt $u$ and of the vapor $u_{v}$ plus losses due to viscous flow of viscosity $\mu$ (plus losses of dissipating momentum and of surface tension to be overcome) to the evaporation recoil pressure $\mathrm{p}_{\mathrm{rec}}$ as the origin.

$$
V \rho u+N_{v} m_{a} u_{v}+\mu \frac{v}{w_{m}}+\frac{\sigma}{r} \geq p_{\text {rec }}
$$

As a next step, streamlines according to Figure 10 and to an earlier model [7] will be studied by applying the time-dependent Bernoulli-equation to the surface forces from curvature. This basically results in an estimation of the relation between mass acceleration and surface tension resistance, according to the surface shape (measurable) as a function of time $\mathrm{z}(\mathrm{x}, \mathrm{y} ; \mathrm{t})$.

Finally, the findings are documented as a Bifurcation Flow Chart (BFC) [8] that we recommend as a standard documentation for combining findings from different research studies in order to establish a common theoretical description of laser welding. The BFC for the here presented study is shown in Figure 11

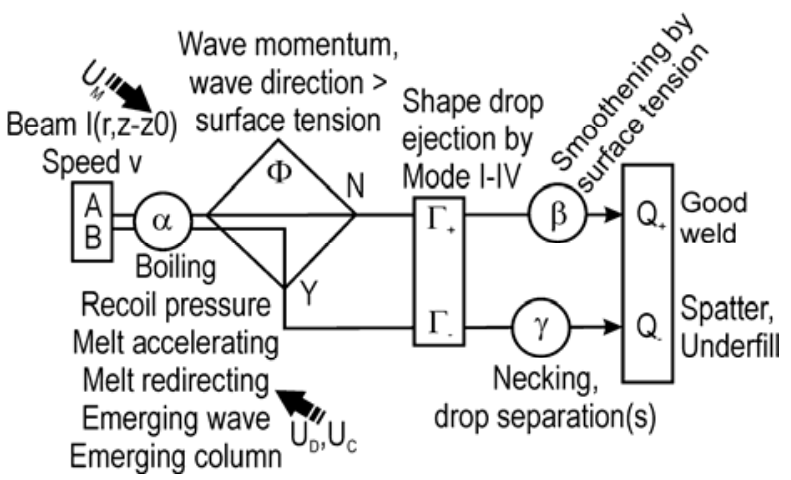

Figure 11 Bifurcation Flow Chart (BFC) qualitatively describing the essential origins of spatter/underfill

The BFC can be read as follows: The defect mechanism Q. under consideration is underfill (accompanied by spatter). High speed imaging $\Gamma$. shows that spatter results from $(\alpha)$ an upflowing part of the melt that $(\gamma)$ breaks into one or more escaping drops provided a threshold criterion $\Phi$ is overcome. As the criterion the momentum component of an upward moving melt wave exceeds the surface tension forces, causing necking and drop separation. Otherwise $(\beta)$ the drop retreats and no defects are formed, as was also observed. This part of the mechanisms $(\beta, \gamma)$ was observed by imaging $\Gamma$ and is fact. Differences were here found for different speed and beams, including $\mathrm{z}_{0}$.

The $\alpha$-mechanisms behind the emerging melt flow are most likely local boiling at the keyhole surface (e.g. due to some local surface motion locally increasing the absorption), inducing strong recoil pressure that accelerates the melt, with a redirected vertical component. The relation to the laser parameters is via the keyhole and thus complex. This part of mechanisms is complex and therefore requires modeling.

\section{Conclusions}

$15 \mathrm{~kW}$ fiber laser welding of $8 \mathrm{~mm}$ thick stainless steel was studied, supported by imaging and modeling.

It can be concluded:

- For achieving full penetration the power has to exceed $5 \mathrm{~kW}$ and a second identified criterion to be fulfilled is $P /(w v d)>30 ~ J / m^{3}$

- Heavy spatter ejection often takes place, causing significant underfill, even at the root side

- Four types of spatter ejection were distinguished, differing in their drop behavior and properties 
- For $15 \mathrm{~kW}$ a focal plane position $\mathrm{z}_{0}$ at or above the surface leads to very regular vertical emerging of a liquid column behind the keyhole, breaking into large escaping drops, leaving a groove/underfill

- For $15 \mathrm{~kW}$ and $\mathrm{z}_{0}=0$, at the front part of the keyhole hardly any melt is seen, the melt pool is slightly wider, the conditions are very confined

- Positioning the focus below the surface created a large keyhole and led to less and smaller spatter

- Half the power (and speed) compared to $15 \mathrm{~kW} \mathrm{/}$ $7 \mathrm{~m} / \mathrm{min}$ created a more favorable melt environment around the keyhole, leading to much less spatter, a calm pool and good weld quality

- Under certain constrained conditions the evaporation recoil pressure becomes periodically strong, with an upward component accelerating and ejecting the melt

- The kinetic drop energy, identified from imaging, is one order of magnitude lower than the energy for surface generation, calculated from the model

- High power/high brightness laser welding has the potential for very narrow, fast welds, provided critical spatter conditions can be avoided

\section{Acknowledgements}

This work was part of the Fibertube project, no. 34012, financed by Vinnova/Jernkontoret within the Strategic Steel Research Program for Sweden. It was also funded by the Knut and Alice Wallenberg Foundation, project no. KAW 2007-0119, by VINNOVA, the Swedish Innovation Agency, project no. 34012 and 2006-00668, and by the Kempe foundation.

\section{References}

[1] Jin, X., Berger, P. \& Graf, Th. (2006) Multiple reflections and Fresnel absorption in an actual 3D keyhole during deep penetration laser welding, J. Phys. D: Appl. Phys. 39, 4703-4712.

[2] Kaplan, A. (1994) A model of deep penetration laser welding based on calculation of the keyhole profile, J. Phys. D: Appl. Phys. 27, 1805-1814.

[3] Abt, F. \& Dausinger, F. (2007) Focusing of high power single mode laser beams, in Proceedings of LIM 4, Munich, Germany, WLT, 321-324.

[4] Vollertsen, F \& Thomy, C. (2005) Welding with fiber lasers from 200 to $17000 \mathrm{~W}$, in Proceedings of ICALEO, Jacksonville, Florida, USA, LIA, 254-263.
[5] Miyamoto, I., Park, S. \& Ooie, T. (2003) Ultrafine keyhole welding processes using single-mode fiber lasers, in Proceedings of LMP: Part A, 203-212.

[6] Kawahito, Y., Mizutani, M. \& Katayama, S. (2007) Elucidation of high-power fiber laser welding phenomena of stainless steel and effect of factors on weld geometry, J. Phys. D: Appl. Phys. 40, 5854-5859.

[7] Kaplan, A., Mizutani, M., Katayama, S. \& Matsunawa, A. (2002) Unbounded keyhole collapse and bubble formation during pulsed laser interaction with liquid zinc, J. Phys. D: Appl. Phys. 35, 1218-1228.

[8] Norman, P. (2008) Process monitoring and analysis of laser welding and of milling, PhD-thesis, Luleå TU, Luleå, Sweden, 131-138.

\section{Meet the Authors}

Alexander Kaplan was born in Vienna, Austria in 1967, employed as researcher at Vienna TU from 1989 until 2000, receiving a $\mathrm{PhD}$-degree in 1994. After a post-doc year at Osaka University, Japan, from 2002 on he has been appointed as professor and head of division on manufacturing at Luleå University of Technology, Sweden. His research focus comprises laser materials processing, in particular process modeling, laser welding and hybrid welding.

Elin M. Westin holds a M.Sc. degree in mechanical engineering from Luleå University of Technology and received her international welding engineer certificate from the Royal Institute of Technology (KTH) in Stockholm, Sweden in 2002. Since then she has been working as a research engineer for Outokumpu Stainless at Avesta Research Center, where she is responsible for weldability research on duplex stainless steels and also an external Ph.D. candidate at KTH.

Greger Wiklund was born in Luleå, Sweden in 1955. He is with Luleå University of Technology as senior researcher in laser materials processing for more than 20 years. His particular research interests focus on laser welding, laser hybrid welding and laser surface treatment.

Peter Norman was born in Luleå in the north of Sweden in 1974. He studied mechanical engineering at Luleå University of Technology, got a Bachelors degree in 1997 and graduated at the Master level in 2002. He worked at a steel mill as researcher for two years, and after that returned to the university as PhDstudent graduating on process monitoring and analysis of laser welding and milling in 2008. 